\title{
Нелинейная фокусировка дискретного волнового фронта с помощью многосердцевинных световодов
}

\author{
И.С. Чеховской ${ }^{1,2, *}$, А.М. Рубенчик ${ }^{3}$, О.В. Штырина ${ }^{1,2}$, \\ С. Вабниц ${ }^{1,4}$, М.П. Федорук ${ }^{1,2}$ \\ ${ }^{1}$ Новосибирский государственный университет, г. Новосибирск \\ ${ }^{2}$ Институт вычислительных технологий СО РАН, г. Новосибирск \\ ${ }^{3}$ Ливерморская национальная лаборатория, Ливермор, итат Калифорния 94550, США \\ ${ }^{4}$ Отдел информационной инженерии, Университет Брешии, Брешиа 25123, Италия \\ *E-mail: i.s.chekhovskoy@gmail.com
}

DOI:10.31868/RFL2018.112-113

В настоящее время исследованию многосердцевинных световодов (multicore fibers - MCF) уделяется большое внимание. Несмотря на то, что основной областью применения данных волокон является передача данных в телекоммуникационных линиях связи, MCF также начали использоваться в лазерных приложениях. В частности, перспективным направлением является изучение фокусировки света с использованием многосердцевинных световодов для создания новых мощных источников оптического излучения. Например, в работе [1] была представлена схема на основе активного гексагонального световода для фокусировки непрерывного излучения в любой наперед заданной сердцевине, для чего использовалось деформируемое зеркало, подстраиваемое с помощью итерационного оптимизационного процесса.

Целью данной работы является демонстрация с помощью численных экспериментов возможности фокусировки и сжатия импульсного лазерного излучения в любой сердцевине 7-сердцевинного гексагонального световода (рис. 1a). Работа является продолжением предыдущих работ, посвященных нелинейному сжатию и сложению оптических импульсов с помощью MCF [2,3].

Динамика огибающих оптических импульсов $U_{n, m}$ в гексагональных многосердцевинных световодах может быть описана с помощью системы связанных нелинейных уравнений Шредингера (НУШ) [3]:

$$
i \frac{\partial U_{n, m}}{\partial z}+\frac{\partial^{2} U_{n, m}}{\partial t^{2}}+(\underline{C U})_{n, m}+\left|U_{n, m}\right|^{2} U_{n, m}=0
$$

где $(\underline{C U})_{n, m}=U_{n-1, m-1}+U_{n+1, m-1}+U_{n-2, m}+U_{n+2, m}+U_{n+1, m-1}+U_{n+1, m+1}-6 U_{n, m}-$ линейные связи сердцевины с номером $(n, m)$. Моделировалось распространение вдоль рассматриваемого 7-сердцевинного световода Гауссовых импульсов $U_{n, m}(z=0, t)=\sqrt{P} \exp \left(-t^{2} /\left(2 \tau^{2}\right)\right) \exp \left(-\phi_{n, m}\right)$. Модель верна для стандартного МСF с коэффициентом связи порядка $10 \mathrm{M}^{-1}$, если длительность импульсов не становится меньше нескольких пикосекунд. В силу наличия линейных связей между импульсами их общее оптическое поле может рассматриваться в качестве дискретного волнового фронта. С помощью подбора фаз каждого импульса в отдельности можно достичь фокусировки поля в любой выбранной сердцевине, при этом керровская нелинейность позволяет эффективно сжимать сфокусированный импульс. Для поиска параметров начальных импульсов, при которых достигается фокусировка импульсов на выходе из отрезка МCF, использовался генетический алгоритм. В качестве целевой функции, значение которой максимизировалось, выступала эффективность сложения импульсов, т.е. отношение энергии сфокусированного импульса без учета энергии, заключенной 
в пьедестале импульса, к полной энергии введенных в светодов импульсов. Для каждого набора значений параметров начальных импульсов, задающих «генотип» особей в генетическом алгоритме, производилось моделирование динамики огибающих этих импульсов для нахождения расстояния вдоль световода, на котором достигается максимальное значение энергии импульса в выбранной сердцевине. Благодаря симметричности расположения сердцевин 7сердцевинного гексагонального световода, рассматривались только два случая: фокусировка в центральной сердцевине и в одной из периферийных.

(a)

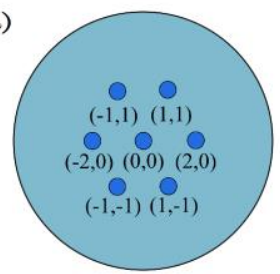

(c)

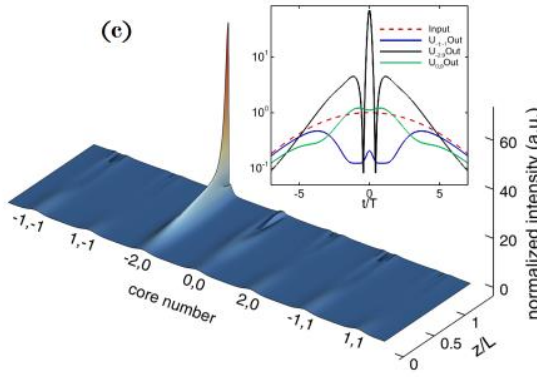

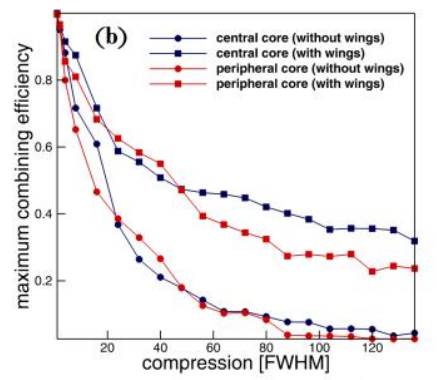

(d)

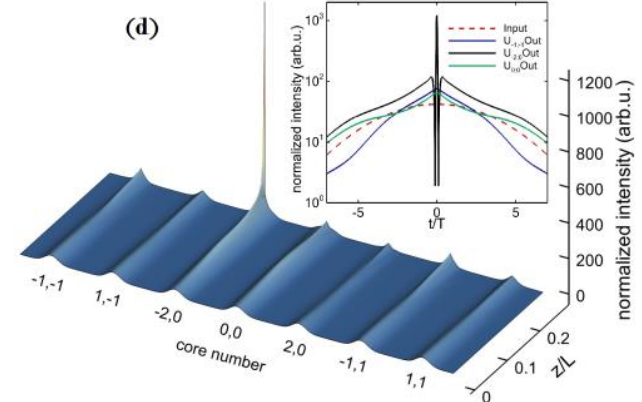

Рис.1. Схема рассматриваемого 7-сердцевинного световода (а). Максимально достижимая эффективность сложения в центральной и периферийной сердцевинах в зависимости от требования к величине сжатия итогового импульса (b). Динамика интенсивности поля в сердцевинах в случае сжатия импульса в 32 раза (c) и в 128 раз (d).

C помощью численного моделирования была найдена максимально достижимая эффективность сложения в центральной и периферийной сердцевинах при заданном требовании к сокращению временной длительности генерируемого импульса по отношению к длительности начальных импульсов (рис. 1b). Было показано, что максимальная эффективность (без учета энергии в пьедестале импульса) сравнима по величине в обоих случаях и экспоненциально уменьшается при росте требования к величине сжатия сфокусированного импульса. Например, импульс, сжатый в 32 раза (рис. 1с), может содержать в своей центральной части максимум около $35 \%$ от общей энергии всех введенных в световод импульсов. Сфокусированный в периферийной сердцевине импульс, сжатый в 128 раз (рис. $1 \mathrm{~d}$ ), может содержать только $3.2 \%$ от общей энергии. Вследствие высокой нелинейности большая часть энергии уходит в пьедестал, поэтому эффективность с учетом энергии в пьедестале достигает $28.5 \%$.

Данная работа была поддержана грантом 14.Y26.31.0017 Министерства образования и науки. Работа выполнена частично при содействии Министерства энергетики США и Ливерморской национальной лаборатории в соответствии с контрактом DE-AC52-07NA27344 (работа A.M. Рубенчика).

\section{Литература}

[1] R. Florentin, et al., Light: Science \& Applications. 6, e16208 (2017)

[2] A. M. Rubenchik, et al., Opt. Lett. 40, 721-724 (2015)

[3] I. S. Chekhovskoy, et. al., Phys. Rev. A 94, 043848 (2016) 